\title{
COMPARISON OF PROPOFOL AND KETOFOL (COMBINATION OF KETAMINE AND PROPOFOL) FOR MODIFIED ELECTROCONVULSIVE THERAPY
}

\author{
Girish Kumar Singh ${ }^{1}$, Dinesh Singh ${ }^{2}$, Reetu Verma ${ }^{3}$, Ajay Kumar Chaudhary4, Vindo Kumar Bhatia 5 , Prithvi Kumar Singh 6 \\ ${ }_{1}^{1}$ Senior Resident, Department of Anaesthesiology, AIIMS, Rishikesh, Uttarakhand, India. \\ 2Professor, Department of Anaesthesiology, King George's Medical University, Lucknow, Uttar Pradesh, India. \\ ${ }^{3}$ Associate Professor, Department of Anaesthesiology, King George's Medical University, Lucknow, Uttar Pradesh, India. \\ 4 Professor, Department of Anaesthesiology, King George's Medical University, Lucknow, Uttar Pradesh, India. \\ ${ }^{5}$ Ret. Professor, Department of Anaesthesiology, King George's Medical University, Lucknow, Uttar Pradesh, India. \\ ${ }^{6}$ SSTA, Department of CFAR, King George's Medical University, Lucknow, Uttar Pradesh, India.
}

\begin{tabular}{l}
\hline ABSTRACT \\
PACKGROUND \\
Propofol and ketamine are used in modified electroconvulsive therapy (ECT) in treating various psychiatric disorders. Propofol \\
to evaluate the effects of propofol and ketofol as an intravenous anaesthetic agent on seizure duration, recovery time and \\
haemodynamic variables during modified electroconvulsive therapy.
\end{tabular}

\section{MATERIALS AND METHODS}

In this prospective study, sixty patients aged 18-65 years with ASA I/II, for psychiatric disorders were included. Patients were divided into two groups (30 each). Group P received propofol and group K received ketofol. Seizure duration, recovery time, haemodynamic variables, complications and side effects were recorded. Data was analysed with SPSS 21 and independent t-test. $\mathrm{p}<0.05$ was considered significant.

\section{RESULTS}

Induction time was significant earlier $(\mathrm{p}<0.001)$ in group $\mathrm{K}(20.23 \pm 6.84$ seconds $)$ as compared to group $\mathrm{P}(33.43 \pm 13.40$ seconds). The mean duration of seizure of patients of group $\mathrm{K}(38.93 \pm 15.26$ seconds) was found to be statistically significantly higher $(\mathrm{p}<0.001)$ than that of group P $(18.10 \pm 5.17$ seconds). The duration of recovery time was significantly earlier $(\mathrm{p}<0.001)$ in group $\mathrm{K}$ $(9.30 \pm 3.01 \mathrm{~min})$ patients as compared to group $\mathrm{P}(18.93 \pm 1.46 \mathrm{~min})$ patients. Patients in Ketofol group were more haemodynamically stable than patients in propofol group.

\section{CONCLUSION}

Ketofol (1:1 Ketamine + propofol mixture) was associated with longer mean seizure, shorter recovery times with better haemodynamic stability as compared to propofol in modified ECT anaesthesia.

\section{KEY WORDS}

Ketofol; Ketamine; Propofol; Efficacy; Safety; Modified Electroconvulsive Therapy.

HOW TO CITE THIS ARTICLE: Singh GK, Singh D, Verma R, et al. Comparison of propofol and ketofol (combination of ketamine and propofol) for modified electroconvulsive therapy. J. Evolution Med. Dent. Sci. 2018;7(47):5102-5106, DOI: $10.14260 /$ jemds/2018/1134

\section{BACKGROUND}

Electroconvulsive therapy (ECT) remains a widely used effective and safe treatment for a variety of complicated psychiatric disorders.[1-3] Almost all ECT procedures are carried out under general anaesthesia with muscle paralysis.[4] The efficacy of ECT in alleviating an acute depression is dependent on the duration of the induced seizure.[3-5] EEG seizure activity lasting from 25 to 75 seconds is alleged to produce the optimal anti-depressant response. Patients experiencing initial seizure duration of 15 seconds (very short) or 120 seconds (very long) achieve a less favorable response to ECT. ${ }^{[5-6]}$ Many anaesthetic drugs used

'Financial or Other Competing Interest': None.

Submission 08-10-2018, Peer Review 01-11-2018,

Acceptance 07-11-2018, Published 19-11-2018.

Corresponding Author:

Dr. Reetu Verma,

Department of Anaesthesiology,

King George's Medical University,

Lucknow-226003, Uttar Pradesh, India.

E-mail: reetuverma1998@gmail.com

DOI: $10.14260 /$ jemds/2018/1134

(c) $($ ) for ECT have anti-convulsant properties and may decrease the duration of ECT-induced seizure activity in a dose dependent manner. Use of larger than necessary dosages results in shorting of the duration of ECT-induced seizure activity and could adversely affect the efficacy of the ECT treatments. A delicate balance needs to be maintained to achieve an adequate anaesthetic state along with an optimal duration of EEG seizure activity. Several anaesthetic agents such as methohexital, etomidate, ketamine, enflurane, thiopental and propofol are used for this purpose, but the ideal anaesthetic agent for ECT procedures remains unclear. ${ }^{[2,}$ 3, 7-11]

Propofol is widely used in ECT anaesthesia as a reference agent due to characteristics such as rapid onset and emergence from anaesthesia, minimal postoperative confusion and a lower incidence of hypertension or tachycardia during induction of anaesthesia. However, it produces a dose-dependent decrease in seizure.[8]

Ketamine, which is an N-methyl-d-aspartate (NMDA) receptor antagonist, is also a noteworthy anaesthetic agent in ECT that has a lesser anticonvulsant effect, favourable seizure induction action and increased seizure duration. ${ }^{[4,12]}$ Also an 
increasing number of studies suggest that ketamine provides an earlier recovery after ECT, and has the potential to reduce retrograde amnesia and accelerate the clinical response to ECT due to its antidepressive action.[13-15] It's main disadvantages are hypertension, delayed recovery and precipitates psychomimetic emergence phenomena.[16]

The opposing effects of ketamine and propofol on the haemodynamics and seizure duration are well known; therefore their side effects on these parameters could be reduced by administering a combination of them at a lower dose.[12] In recent studies done on patients undergoing ECT, it showed that using sub-anaesthetic ketamine and low-dose propofol increase the seizure duration, provide haemodynamic stability and earlier recovery compared with the use of a full dose of propofol alone. Therefore, we evaluate the effects of ketofol (ketamine+propofol) and propofol as a better induction agent for modified ECT. The primary aim of the study was to compare seizure duration between the two groups and the secondary aims of the study were to compare induction time, haemodynamic stability, recovery time, complications and side effects.

\section{MATERIALS AND METHODS}

\section{Study Design}

This prospective randomized comparative study was carried out after obtaining the approval from the institutional ethical committee. This study was also registered in clinical trials registry India (CTRI) with CTRI No. CTRI/2018/03/01234. A total 60 patients with ASA grade I or II, age 18 to 65 years were included in this study. The sample size was calculated on the basis of $80 \%$ power of study (beta 0.20 ) and $5 \%$ alpha risk which showed that 30 patients per study groups were needed. The study was carried in psychiatry department incollaboration with department of Anaesthesiology from September 2016 to August 2017. Written informed consent was obtained from all the patients. Patients with history of allergic reaction to any drugs, respiratory disorders, uncontrolled hypertension, epilepsy, cardiovascular diseases, intracranial hypertension, cerebral vascular disorder, uncontrolled diabetes, history of heart block and hypertension and chronic pain syndrome were excluded from the study.

Patients were randomized in to two groups $(n=30$ in each group) using computer generated random number table.

Group K- Injection (Inj.) Ketofol 0.5 to $1 \mathrm{mg} / \mathrm{kg}[10 \mathrm{mg} / \mathrm{ml}$ in $10 \mathrm{ml}$ syringe i.e. $50 \mathrm{mg}(1 \mathrm{ml})$ ketamine $+50 \mathrm{mg}(5 \mathrm{ml})$ propofol $+4 \mathrm{ml}$ Normal saline], Ketamine:Propofol::1:1 Ratio

Group P- Injection (Inj.) Propofol 0.5 to $1 \mathrm{mg} / \mathrm{kg}[10 \mathrm{mg} / \mathrm{ml}$ in $10 \mathrm{ml}$ syringe]

On arrival to ECT procedure room, patient's baseline heart rate (HR), systolic blood pressure (SBP), diastolic blood pressure (DBP), mean arterial pressure (MAP) and electrocardiogram and oxygen saturation $\left(\mathrm{SpO}_{2}\right)$ were recorded and adequate NPO status was ensured. A 20G intravenous line was established and infusion was started with ringer lactate solution. Haemodynamic parameters were measured on arrival and at every 2 min thereafter till the end of procedure. All patients were premedicated with Inj. ondansetron $4 \mathrm{mg}$ IV, Inj. glycopyrrolate $0.2 \mathrm{mg}$ IV all patients pre-oxygenated with $100 \% \mathrm{O}_{2}$ for 3 to $5 \mathrm{~min}$ and then induction was done with intravenous (I.V.) anaesthetic agent, Inj. propofol 0.5 to $1 \mathrm{mg} / \mathrm{kg}$ I.V. in group P and Inj. Ketofol 0.5 to $1 \mathrm{mg} / \mathrm{kg}$ I.V.in group $\mathrm{K}$ and induction time was noted.

This was followed by Inj. Succinylcholine $0.5 \mathrm{mg} / \mathrm{kg}$ to 1 $\mathrm{mg} / \mathrm{kg}$ intravenously. Controlled Ventilation was given with a facemask and Bain circuit with 100\% Oxygen. Bite block was put before application of the electrical stimulus to protect patient's teeth and minimize the risk of laceration of the tongue and patient was tightly hold for immobilization to prevent fracture and other complications when ECT was given.

Haemodynamic changes (Heart rate, systolic blood pressure (SBP), diastolic blood pressure (DBP), mean arterial pressure (MAP), electrocardiogram and oxygen saturation (Sp02) were recorded at every $2 \mathrm{~min}$, duration of seizure (SD) and recovery time (RT) were also noted. All patients were given $100 \%$ Oxygen after convulsions and ventilated by IPPV via bag and mask till return of spontaneous respiration. Recovery was observed by regain of reflexes, response to pain and verbal commands. Patients were shifted to the recovery room when they start obeying verbal commands and their vitals are stable. Patients were monitored and assessed during and after ECT for complications like nausea, vomiting, hypotension, bradycardia, arrhythmias, desaturation, laryngospasm, hypersensitivity reaction etc.

All statistical analyses were performed using SPSS 15.0 windows software. The sample size was calculated on the basis of $80 \%$ power of the study. Comparisons between groups at different time intervals were assessed by using student " $\mathrm{t}$ " test. All the categorical data was compared by using chi square test. Changes over time between two groups at different point of time was calculated by repeated ANOVA. Parametric data was compared using chi square test. A pvalue of $<0.05$ was considered to be significant.

\section{RESULTS}

The demographic profiles age, gender, weight, and ASA grade were similar in both groups as shown in Table 1. Mean age of patients of group $\mathrm{K}(35.20 \pm 10.55$ years $)$ was found to be higher than that of group P $(35.37 \pm 14.64$ years $)$. Majority of patients $60.0 \%$ in group $\mathrm{K}$ and $73.33 \%$ patients in group $\mathrm{P}$ were male. Mean difference in body weight of patients of group K $(58.93 \pm 8.55 \mathrm{~kg})$ and group P $(60.70 \pm 9.55 \mathrm{~kg})$ was not found to be statistically significant. Physical status of majority of the patients enrolled in the study was ASA grade I $(81.67 \%)$ and rest were assessed as grade II. Though proportion of patients of grade II was higher in group $\mathrm{K}$ $(20.00 \%)$ as compared to group P (16.67\%), this difference was not found to be statistically significant (Table 1).

Induction time was significantly earlier $(\mathrm{p}<0.001)$ in group $\mathrm{K}(20.23 \pm 6.84$ seconds $)$ as compared to group $\mathrm{P}$ (33.43 \pm 13.40 seconds) as shown in table 2 . The mean duration of seizure of patients of group K $(38.93 \pm 15.26$ seconds) was found to be statistically significantly higher $(p<0.001)$ than that of group $P(18.10 \pm 5.17$ seconds $)$ as shown in Table 2. The duration of recovery time was significantly earlier $(\mathrm{p}<0.001)$ in group $\mathrm{K}(9.30 \pm 3.01 \mathrm{~min})$ patients as compared to group $\mathrm{P}(18.93 \pm 1.46 \mathrm{~min})$ patients (Table 2).

Heart rate (HR) was higher in group $\mathrm{K}$ as compared to group $\mathrm{P}$ at baseline, $2 \mathrm{~min}, 16 \mathrm{~min}, 18$ and $20 \mathrm{~min}$ while, at rest of the periods 4 to $14 \mathrm{~min}$, heart rate was higher in group $\mathrm{P}$ as compared to group K. Difference in heart rate was found 
to be statistically significant $(<0.001)$ in between group $\mathrm{K}$ and group $\mathrm{P}$ at $6 \mathrm{~min}(97.07 \pm 14.87$ vs. 104.07 per $\mathrm{min}), 8 \mathrm{~min}$ $(97.65 \pm 15.44$ vs $112.53 \pm 10.80$ per $\mathrm{min}$ ) and $10 \mathrm{~min}$ ( $100.83 \pm 14.53$ vs. $116.07 \pm 13.94$ per min) (Fig. 1$)$. Change in baseline heart rate was maximum at $6 \min (12.63 \pm 8.50$ per $\mathrm{min})$ in group $\mathrm{K}$ whereas at $22 \mathrm{~min}(37.00 \pm 1.41$ per $\mathrm{min})$ in group $\mathrm{P}$. Change in baseline heart rate was statistically significant $(<0.001)$ at $2 \mathrm{~min}-14 \mathrm{~min}$ in group $\mathrm{K}$ whereas at 2 $\min -22$ min in group $P$.

Mean systolic blood pressure (SBP) of patients was found to be higher in group $\mathrm{K}$ as compared to group $\mathrm{P}$ at baseline while at rest of the periods; SBP was higher in group $\mathrm{P}$ as compared to group $\mathrm{K}$ at $2 \mathrm{~min}$ to $22 \mathrm{~min}$. Difference in SBP was statistically significant $(<0.001)$ in between group and group $\mathrm{P}$ at $6 \mathrm{~min}$ to $14 \mathrm{~min}, 18 \mathrm{~min}$ and $20 \mathrm{~min}$ (Fig. 2). Change in baseline SBP was maximum at 4 min $(11.33 \pm 6.99$ $\mathrm{mm} \mathrm{Hg})$ in group $\mathrm{K}$ whereas at $8 \mathrm{~min}(24.67 \pm 16.06 \mathrm{~mm} \mathrm{Hg})$ in group P. Change in baseline SBP was found to be statistically significant $(<0.001)$ during $2 \mathrm{~min}-10 \mathrm{~min}$ in group $\mathrm{K}$. Whereas it was found to be statistically significant $(<0.001)$ during $2 \mathrm{~min}-20 \mathrm{~min}$ in group $\mathrm{P}$.

At baseline diastolic blood pressure (DBP) was higher in group $\mathrm{K}$ than group $\mathrm{P}$ while at rest of the periods of observation mean DBP was higher in group $\mathrm{P}$ than group $\mathrm{K}$. Difference in mean diastolic BP was statistically significant $(<0.001)$ in between group $\mathrm{K}$ and group $\mathrm{P}$ at periods of observation between $6 \mathrm{~min}$ to $14 \mathrm{~min}, 18 \mathrm{~min}$ and $20 \mathrm{~min}$ (Fig. 3). Maximum change in baseline DBP was observed at 14 $\min (3.43 \pm 4.86 \mathrm{~mm} \mathrm{Hg})$ in group $\mathrm{K}$ whereas at $8 \mathrm{~min}$ $(15.80 \pm 7.49 \mathrm{~mm} \mathrm{Hg}$ ) in group P. Change in baseline DBP was found to be statistically significant $(<0.001)$ during 2 min and 4 min in group K. Whereas it was found to be statistically significant $(<0.001)$ during $2 \mathrm{~min}-20 \mathrm{~min}$ in group $\mathrm{P}$.

Differences in Oxygen saturation level were not found to be statistically significant $(>0.05)$ in between group $\mathrm{K}$ and group $\mathrm{P}$ at any of the periods of observation. Oxygen saturation level of all the patients was $>95 \%$ at all the periods of observation. Abnormality in ECG was not observed in any of the patients of either group at any period of observation. There were not observed any side effects in any of the patient in group $\mathrm{K}$ and group $\mathrm{P}$.

\begin{tabular}{|c|c|c|c|}
\hline & $\begin{array}{c}\text { Group K } \\
(n=30)\end{array}$ & $\begin{array}{c}\text { Group P } \\
(n=30)\end{array}$ & p-Value \\
\hline Age & $35.20 \pm 10.55$ & $35.37 \pm 14.64$ & 0.460 \\
\hline \multicolumn{4}{|c|}{ Gender } \\
\hline Female & $12(40.0 \%)$ & $8(26.67 \%)$ & \multirow{2}{*}{0.272} \\
\hline Male & $18(60.0 \%)$ & $22(73.33 \%)$ & \\
\hline Weight & $58.93 \pm 8.55)$ & $60.70 \pm 9.55$ & 0.453 \\
\hline \multicolumn{4}{|c|}{ ASA Grade } \\
\hline $\mathrm{I}$ & $24(80.0 \%)$ & $25(83.33 \%)$ & \multirow{2}{*}{0.739} \\
\hline II & $6(20.0 \%)$ & $5(16.67 \%)$ & \\
\hline
\end{tabular}

Data are represented as mean, $\pm \mathrm{SD}, \mathrm{n}(\%)$ and ratio. $\mathrm{SD}=$ Standard deviation.

\begin{tabular}{|c|c|c|c|}
\hline & $\begin{array}{c}\text { Group K } \\
(\mathbf{n = 3 0 )}\end{array}$ & $\begin{array}{c}\text { Group P } \\
\text { (n=30) }\end{array}$ & p-Value \\
\hline Induction Time & $20.23 \pm 6.84)$ & $33.43 \pm 13.40$ & $<0.001^{* *}$ \\
\hline $\begin{array}{c}\text { Seizure Duration } \\
\text { (sec) }\end{array}$ & $38.93 \pm 15.26$ & $18.10 \pm 5.17$ & $<0.001^{* *}$ \\
\hline $\begin{array}{c}\text { Recovery Time } \\
\text { (min) }\end{array}$ & $9.30 \pm 3.01$ & $18.93 \pm 1.46$ & $<0.001^{* *}$ \\
\hline
\end{tabular}

Table 2. Seizure Duration and Recovery Times of Patients
${ }^{* *}=$ Significant $(\mathrm{p}=<0.001)$

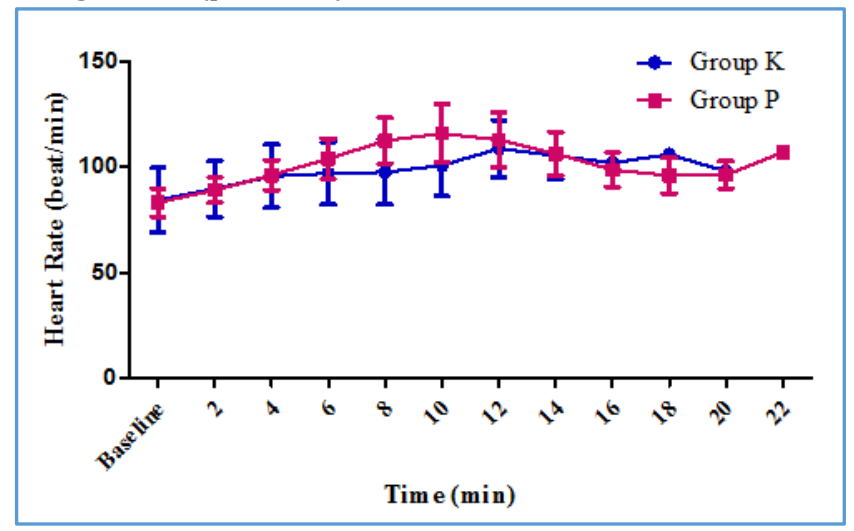

Figure 1. Heart Rate (HR) Beats/Min

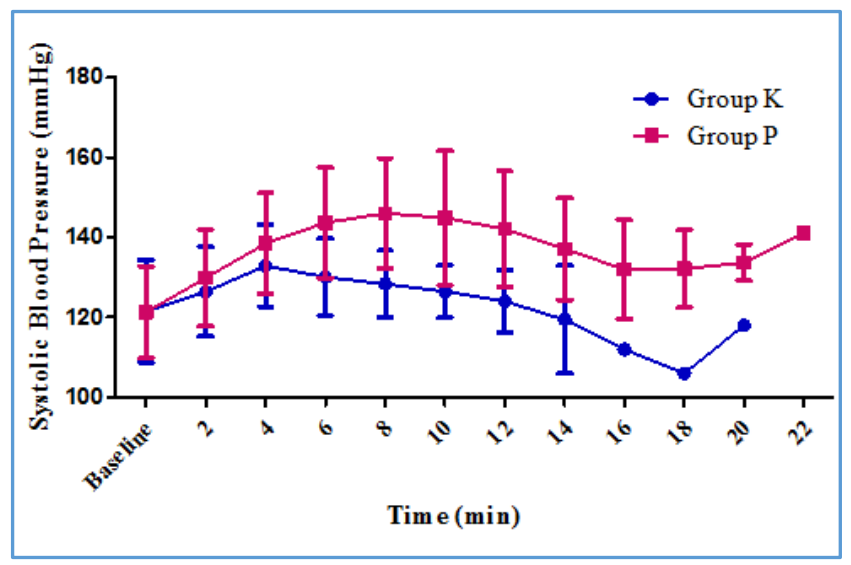

Figure 2. Systolic Blood Pressure (SBP) $\mathrm{mmHg}$

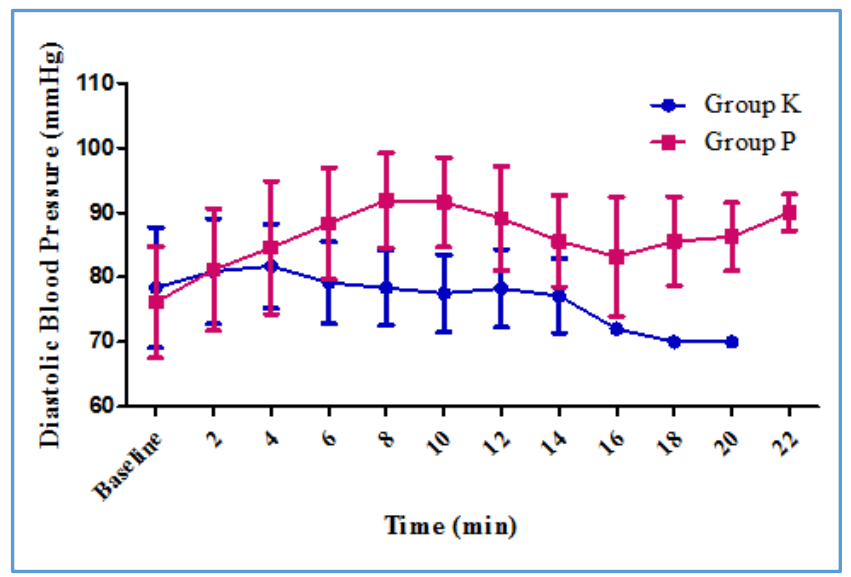

Figure 3. Diastolic Blood Pressure (DBP) $\mathrm{mmHg}$

\section{DISCUSSION}

In recent years, ECT has assumed an increasingly important role in the treatment of severe and medication-resistant depression and mania as well as in the treatment of schizophrenic patients with affective disorders, delusional symptoms, vegetative dysregulation, inanition, catatonic symptoms and suicidal drive. ${ }^{[1-15]}$ Now a days modified ECT is used under general anaesthesia by giving various anaesthetic agents like thiopentone, propofol, ketamine, dexmedetomidine, etomidate, ketofol etc.

In this study we found that the increased seizure duration, rapid recovery and better haemodynamic stability in ketofol group as compared with propofol group. Our 
results are supported by similar findings of various previous studies, who reported that the ketofol is associated with greater seizure duration.[17-19] Based on this finding which is consistent with observations made by Kayhan et al. (2012), it appears that ketofol can be an alternative to enhance seizure quality and clinical efficacy of modified ECT.[12] Consequently, ketofol may be useful in patients in whom it is difficult to elicit a robust seizure. This can be explained on the basis of the pro-convulsant effects of ketamine.[20] The propofol combined with ketamine as an ECT anaesthesia has no negative effects on the inherent antidepressant properties of ketamine. Moreover, the combined anaesthesia could reduce ketamine-mediated adverse effects.[21] The anticonvulsive properties of propofol, which are known to exert a relevant influence on seizure quality and treatment outcome, did not decrease the rapid antidepressant properties of ketamine, as shown by the higher and longer seizure duration in groups ketamine or propofof + ketamine compared with those in group propofol during ECT. [22, 23]

In present study the recovery time was significantly earlier in ketofol group as compared to propofol group. Our observations are supported by Amornyotin, (2014), who reported that the combination of propofol and ketamine has several benefits because of lack of good recovery, respiratory depression.[24] The Ketofol (ketamine + propofol) is widely used in ECT anaesthesia and is reported to have better cognitive recovery and better antidepressant effects.[21]

In this study, ketofol group was shown more haemodynamic stability during modified ECT as compared to propofol group. Our study was supported by previous studies which reported that the ketofol provides better haemodynamic stability as compared to propofol in ECT.[4, 19, 25] Ketofol may also provide a better haemodynamic stability compared with the ketamine alone. A previous study reported that the ketofol was producing a more stable haemodynamic in group of healthy patients receiving general anaesthesia.[26] Whereas Jaitawat et al. (2016) reported that the heart rates were comparable in both ketofol and propofol groups.[19]

In the present study we observed that there were no complication such as nausea, vomiting, hypotension, bradycardia, arrhythmias, desaturation, laryngospasm, hypersensitivity reaction etc. observed in ketofol or propofol groups. Similarly, Yalcin et al. (2012) reported that the ketofol was not associated with any important side effects in ECT anaesthesia. [4] A recent study have also reported that there was no significant side effects were observed in the propofol, etomidate or ketofol groups[19]. In a study by Wang et al. (2012) showed that the adverse effects in propofol plus ketamine group were fewer than those in ketamine group.[21] This study suggests that ketofol (propofol+ketamine) is better anaesthetic agent than propofol in patients undergoing modified ECT.

\section{CONCLUSION}

In patients undergoing modified ECT, ketofol provides lesser induction time, better haemodynamic stability, longer seizure duration, earlier and smooth recovery as compared to propofol. Further research with ketofol in ECT is warranted. Additional studies with larger groups of patients, investigating optimal doses, antidepressant effects, cognitive function-preserving effect and physician satisfaction scores must be elucidated.

\section{REFERENCES}

[1] Feliu M, Edwards CL, Sudhakar S, et al. Neuropsychological effects and attitudes in patients following electroconvulsive therapy. Neuropsychiatr Dis Treat 2008;4(3):613-7.

[2] Uppal V, Dourish J, Macfarlane A. Anaesthesia for electroconvulsive therapy. Contin Educ Anaesth Crit Care Pain 2010;10(6):192-6.

[3] Ding Z, White PF. Anaesthesia for electroconvulsive therapy. Anesth Analg 2002;94(5):1351-64.

[4] Yalcin S, Aydoğan H, Selek S, et al. Ketofol in electroconvulsive therapy anaesthesia: two stones for one bird. J Anesth 2012;26(4):562-7.

[5] Geretsegger C, Rochowanski E, Kartnig C, et al. Propofol and methohexital as anaesthetic agents for electroconvulsive therapy (ECT): a comparison of seizure-quality measures and vital signs. J ECT 1998;14(1):28-35.

[6] Villalonga A, Bernardo M, Gomar C, et al. Cardiovascular response and anaesthetic recovery in electroconvulsive therapy with propofol or thiopental. Convuls Ther 1993;9(2):108-11.

[7] Kumar A, Sharma DK, Mani R. A comparison of propofol and thiopentone for electroconvulsive therapy. J Anaesthesiol Clin Pharmacol 2012;28(3):353-7.

[8] Dogan Z, Senoglu N, Yildiz H, et al. Comparison of enflurane and propofol in electroconvulsive therapy, a randomized crossover open preliminary study on seizure duration and anaesthetic recovery. Rev Bras Anestesiol 2011;61(5):582-90, 319-23.

[9] Geretsegger C, Nickel M, Judendorfer B, et al. Propofol and methohexital as anaesthetic agents for electroconvulsive therapy: A randomized, doubleblind comparison of electroconvulsive therapy seizure quality, therapeutic efficacy and cognitive performance. J ECT 2007;23(4):239-43.

[10] Kranaster L, Kammerer-Ciernioch J, Hoyer C, et al. Clinically favourable effects of ketamine as an anaesthetic for electroconvulsive therapy: a retrospective study. Eur Arch Psychiatry Clin Neurosci 2011;261(8):575-82.

[11] Rosa MA, Rosa MO, Belegarde IM, et al. Recovery after ECT: comparison of propofol, etomidate and thiopental. Bras J Psychiatr 2008;30(2):149-51.

[12] Kayhan GE, Yucel A, Colak YZ, et al. Ketofol (mixture of ketamine and propofol) administration in electroconvulsive therapy. Anaesth Intensive Care 2012;40(2):305-10.

[13] Gregory-Roberts EM, Naismith SL, Cullen KM, et al. Electroconvulsive therapy-induced persistent retrograde amnesia: Could it be minimised by ketamine or other pharmacological approaches? J Affect Disord 2010;126(1-2):39-45. 
[14] MacPherson RD, Loo CK. Cognitive impairment following electroconvulsive therapy-does the choice of anaesthetic agent makes a difference? J ECT 2008;24(1):52-6.

[15] Okamoto N, Nakai T, Sakamoto $K$, et al. Rapid antidepressant effect of ketamine anaesthesia during electroconvulsive therapy of treatment-resistant depression: comparing ketamine and propofol anaesthesia. J ECT 2010;26(3):223-7.

[16] Mahajan R, Swarnkar N, Ghosh A. Comparison of ketamine and fentanyl with propofol in total intravenous anaesthesia: a double blind randomized clinical trial. Internet J Anesthesiol 2010:23.

[17] Simpson KH, Halsall PJ, Carr CM, et al. Propofol reduces seizure duration in patients having anaesthesia for electroconvulsive therapy. British Journal of Anaesthesia 1988;61(3):343-4.

[18] Zahavi GS, Dannon P. Comparison of anaesthetics in electroconvulsive therapy: an effective treatment with the use of propofol, etomidate and thiopental. Neuropsychiatr Dis Treat 2014;10:383-9.

[19] Jaitawat SS, Sharma M, Mathur DM, et al. A comparative study of haemodynamic effects, recovery pattern and seizure activity of propofol, ketofol and etomidate in modified electroconvulsive therapy. International Journal of Contemporary Medical Research 2016;3(3):759-63.
[20] Krystal AD, Weiner RD, Dean MD, et al. Comparison of seizure duration, ictal EEG, and cognitive effects of ketamine and methohexital anaesthesia with ECT. J Neuropsychiatry Clin Neurosci 2003;15(1):27-34.

[21] Wang X, Chen Y, Zhou X, et al. Effects of propofol and ketamine as combined anaesthesia for electroconvulsive therapy in patients with depressive disorder. J ECT 2012;28(2):128-32.

[22] Bundy BD, Hewer W, Andres FJ, et al. Influence of anaesthetic drugs and concurrent psychiatric medication on seizure adequacy during electroconvulsive therapy. J Clin Psychiatry 2010;71(6):775-7.

[23] Sartorius A, Munoz-Canales EM, Krumm B, et al. ECT anaesthesia: the lighter the better? Pharmacopsychiatry 2006;39(6):201-4.

[24] Amornyotin S. Ketofol: a combination of ketamine and propofol. J Anesth Crit Care: Open Access 2014;1(5):00031.

[25] Firouzian A, Tabassomi F. Is ketamine-propofol mixture (ketofol) an appropriate alternative induction agent for electroconvulsive therapy? Saudi J Anaesth 2013;7(4):476-7.

[26] Morse Z, Sano K, Kanri T. Effects of a propofolketamine admixture in human volunteers. Pac Health Dialog 2003;10(1):51-4. 